Wright State University

CORE Scholar

$5-1-2002$

\title{
Depth-Dependent Investigation of Defects and Impurity Doping in GaN/Sapphire Using Scanning Electron Microscopy and Cathodoluminescence Spectroscopy
}

\author{
X. L. Sun \\ S. H. Goss \\ L. J. Brillson \\ David C. Look \\ Wright State University - Main Campus, david.look@wright.edu \\ Richard J. Molnar
}

Follow this and additional works at: https://corescholar.libraries.wright.edu/physics

Part of the Physics Commons

\section{Repository Citation}

Sun, X. L., Goss, S. H., Brillson, L. J., Look, D. C., \& Molnar, R. J. (2002). Depth-Dependent Investigation of Defects and Impurity Doping in GaN/Sapphire Using Scanning Electron Microscopy and Cathodoluminescence Spectroscopy. Journal of Applied Physics, 91 (10), 6729-6738. https://corescholar.libraries.wright.edu/physics/153

This Article is brought to you for free and open access by the Physics at CORE Scholar. It has been accepted for inclusion in Physics Faculty Publications by an authorized administrator of CORE Scholar. For more information, please contact library-corescholar@wright.edu. 


\title{
Depth-dependent investigation of defects and impurity doping in GaN/sapphire using scanning electron microscopy and cathodoluminescence spectroscopy
}

\author{
X. L. Sun and S. H. Goss \\ Department of Electrical Engineering, Ohio State University, 205 Dreese Lab, 2015 Neil Avenue, \\ Columbus, Ohio 43210 \\ L. J. Brillson \\ Department of Electrical Engineering, Center for Materials Research, and Department of Physics, \\ Ohio State University, 205 Dreese Lab, 2015 Neil Avenue, Columbus, Ohio 43210 \\ D. C. Look \\ Semiconductor Research Center, Wright State University, Dayton, Ohio 45435 \\ R. J. Molnar \\ Lincoln Laboratory, Massachusetts Institute of Technology, Lexington, Massachusetts 02420
}

(Received 3 August 2001; accepted for publication 2 January 2002)

Cathodoluminescence (CL) imaging and temperature-dependent cathodoluminescence spectroscopy (CLS) have been used to probe the spatial distribution and energies of electronic defects near $\mathrm{GaN} / \mathrm{Al}_{2} \mathrm{O}_{3}$ interfaces grown by hydride vapor phase epitaxy (HVPE). Cross sectional secondary electron microscopy imaging, CLS, and CL imaging show systematic variations in defect emissions with a wide range of HVPE GaN/sapphire electronic properties. These data, along with electrochemical capacitance-voltage profiling and secondary ion mass spectrometry provide a consistent picture of near-interface doping by $\mathrm{O}$ out-diffusion from $\mathrm{Al}_{2} \mathrm{O}_{3}$ into $\mathrm{GaN}$ over hundreds of nanometers. Low-temperature CL spectra exhibit a new donor level at $3.447 \mathrm{meV}$ near the interface for such samples, characteristic of $\mathrm{O}$ impurities spatially localized to the nanoscale interface. CLS emissions indicate the formation of amorphous $\mathrm{Al}-\mathrm{N}-\mathrm{O}$ complexes at $3.8 \mathrm{eV}$ extending into the $\mathrm{Al}_{2} \mathrm{O}_{3}$ near the $\mathrm{GaN} /$ sapphire interface. CLS and CL images also reveal emissions due to excitons bound to stacking faults and cubic phase GaN. The temperature dependence of the various optical transitions in the 10-300 K range provides additional information to identify the near interface defects and impurity doping. (C) 2002 American Institute of Physics. [DOI: $10.1063 / 1.1454187]$

\section{INTRODUCTION}

The group III-nitrides are attractive materials for optoelectronic devices such as GaN-based lasers, light-emitting diodes $^{1}$ and ultraviolet photodetectors, ${ }^{2}$ and high temperature, high power electronic devices. ${ }^{3}$ Present and future applications of GaN-based devices require the further development of the materials technology as well as the physical understanding of the materials involved. Epitaxial growth of GaN by hydride vapor epitaxy (HVPE) was developed in the 1960s. ${ }^{4}$ Thick, bulk-like HVPE material is suitable for studies of GaN's physical properties, as well as acting as a lattice-matched substrate for device epilayers grown by metal-organic chemical vapor deposition (MOCVD) ${ }^{5}$ and molecular beam epitaxy (MBE). However, electronically active defects within this material are poorly understood, for instance, the nature of the residual acceptor and donor ${ }^{6,7}$ and the identification of various emissions related to defects. ${ }^{8}$

The states localized at the interface of GaN/sapphire can be of significant concern for certain device applications. In particular, degenerate doping and high conductance ${ }^{9,10}$ can occur near this interface with sapphire, potentially affecting lateral transport in the overgrown device. Hence, impurity diffusion, interface reaction, and related defect formation are important to understand and control. The physical origin of the donors has until now been unclear since it may involve: (i) impurities substrate out-diffusion ${ }^{11-13}$ or the initial growth surface, (ii) native defects induced by substrate out-diffusion or the initial growth surface, (iii) morphological structural effects, and (iv) gas phase impurities. In order to determine the physical nature of these dopants and defects, we used temperature-dependent $(10-300 \mathrm{~K})$ electron-excited luminescence spectroscopy in an ultrahigh vacuum (UHV) scanning electron microscope (SEM) to measure defect emissions from $\mathrm{GaN} / \mathrm{Al}_{2} \mathrm{O}_{3}$ junctions with sheet carrier densities that varied over two orders of magnitude. We carried out cross sectional secondary electron (SE) imaging, cathodoluminescence spectroscopy (CLS), and CL imaging of these interfaces. We used electrochemical capacitance-voltage (ECV) profiling to measure epitaxial sheet carrier densities $N_{\text {int }}$ localized near the junctions. Depth-dependent CLS and CL images provide information for detecting the location and physical origin of defects and impurity doping at $\mathrm{GaN} / \mathrm{Al}_{2} \mathrm{O}_{3}$ interfaces. This study focuses on the spectral variations of defects and doping features as a function of depth to the interface. Our aim is to establish the nature of the optical 
transitions due to defects and impurity doping in $\mathrm{GaN} / \mathrm{Al}_{2} \mathrm{O}_{3}$, especially near interfaces.

\section{EXPERIMENTS}

The HVPE GaN epitaxy layers deposited on $c$-plane sapphire were obtained from several sources, designated A $\left(A_{1}, A_{2}\right), B$, and $C$. These layers had sheet interface concentrations, as determined from low-temperature Hall-effect measurements, of $6,16,98$, and $508 \times 10^{14} \mathrm{~cm}^{-2}$, for $\mathrm{A}_{1}$, $\mathrm{A}_{2}, \mathrm{~B}$, and $\mathrm{C}$, respectively, designated as "low" (for $\mathrm{A}_{1}$ and $\mathrm{A}_{2}$ ), "medium," and "high." Source A material incorporated a $\mathrm{ZnO}$ buffer layer prior to GaN growth, whereas the others did not. The $\mathrm{ZnO}$ layer was sputter deposited to prepare the sapphire substrate for GaN growth and was thermally desorbed before epitaxial growth. ${ }^{14}$ A modified JEOL 7800F SEM Auger microprobe (base pressure $8 \times 10^{-11}$ Torr) fitted with an Oxford Scientific monochromator with a resolution of $0.5 \mathrm{~nm}$, liquid He cold stage, and visible-UV sensitive photomultiplier tube provided CL spectra and images. All windows and lenses were UV transparent. Spectra were corrected for the transmission and detection efficiency of the optical transmission. We produced cross sections by scoring the sapphire and cleaving between glass cover slips. The room temperature secondary electron image (SEI) and CLS measurement were taken using an electron beam energy of $15 \mathrm{keV}$ and current of $100 \mathrm{pA}$ over an area of one $\mu \mathrm{m}^{2}$. For the low temperature experiments, the incident electron beam energy was $5 \mathrm{keV}$ and current was $1 \mathrm{nA}$ over an area less than $0.5 \times 0.5 \mu \mathrm{m}^{2}$ raster square area. Due to the acceleration voltage, excitation occurred $\sim 160 \mathrm{~nm}$ below the surface to minimize any surface artifacts. Depth-dependent CL spectra were taken as a function of the distance $\left(d_{\text {int }}\right)$ from the $\mathrm{GaN} / \mathrm{Al}_{2} \mathrm{O}_{3}$ interface.

\section{LOW SHEET CARRIER CONCENTRATION}

CL spectra of low sheet carrier concentration $\left(N_{\text {int }}\right) \mathrm{GaN}$ display large variations in deep level and near band edge (NBE) emissions as a function of distance from the interface. SE images of the sample cross sections provide spatial detail of the semiconductor and substrate boundaries. ${ }^{15}$ Similar variations are evident for all of the samples studied. These room temperature data also illustrate the experimental method used to measure optical emissions versus distance for all the samples. Figure 1 illustrates the SE image of an HVPE-grown $\mathrm{GaN} / \mathrm{Al}_{2} \mathrm{O}_{3}$ cross section (sample $\mathrm{A}_{1}$ ). The dark area at the lower right corresponds to the sapphire substrate, whereas the bright line at the upper left indicates the free GaN surface. The bright area in the upper left is the sample holder. The striations extending across the GaN thickness are due to cleavage steps but have little effect on the CL spectra obtained with bulk sensitive electron beam energies of 5-15 keV. The numbered dots shown in Fig. 1 indicate the positions at which CL spectra were acquired. The number on each side of every point in Fig. 1 indicates the distance $\left(d_{\text {int }}\right)$ from the GaN/sapphire interface in microns. The negative values refer to positions within the sapphire. From the variation in intensities with distance from the interface, it was possible to generate profiles for each CL

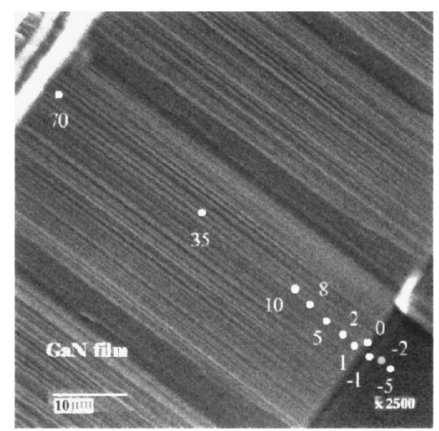

FIG. 1. Secondary electron image of the GaN film grown by HVPE on sapphire. The sapphire substrate is the dark region in the lower right corner of the image. Each dot on the SEM image represents an area where a CL spectrum was taken.

spectral feature relative to distance from the interface. Figure 2 illustrates the intensity profiles for each of the luminescence features measured versus distance from the GaN/ sapphire interface. The inset to Fig. 2 displays a typical room temperature $\mathrm{CL}$ spectrum for the $\mathrm{HVPE} \mathrm{GaN} / \mathrm{Al}_{2} \mathrm{O}_{3}$ sample interface, showing peak features at 3.8, 3.4, 2.95, and $2.2 \mathrm{eV}$. (Note that the 1.7- and 1.9-eV lines are just second-order transitions while the sharp peak at $1.78 \mathrm{eV}$ is $\mathrm{Cr}$ emission from sapphire.) The 3.4, 2.95, and $2.2 \mathrm{eV}$ features correspond to well-known emissions of the GaN near band edge (NBE), blue luminescence (BL), and yellow luminescence (YL), respectively.

As the inset of Fig. 2 shows, the NBE, YL, 3.8, and BL peaks exhibit Gaussian line shapes in log scale spectra at the energies shown. Their relative peak intensities appear as a function of raster center distance $d_{\text {int }}$ from the interface in

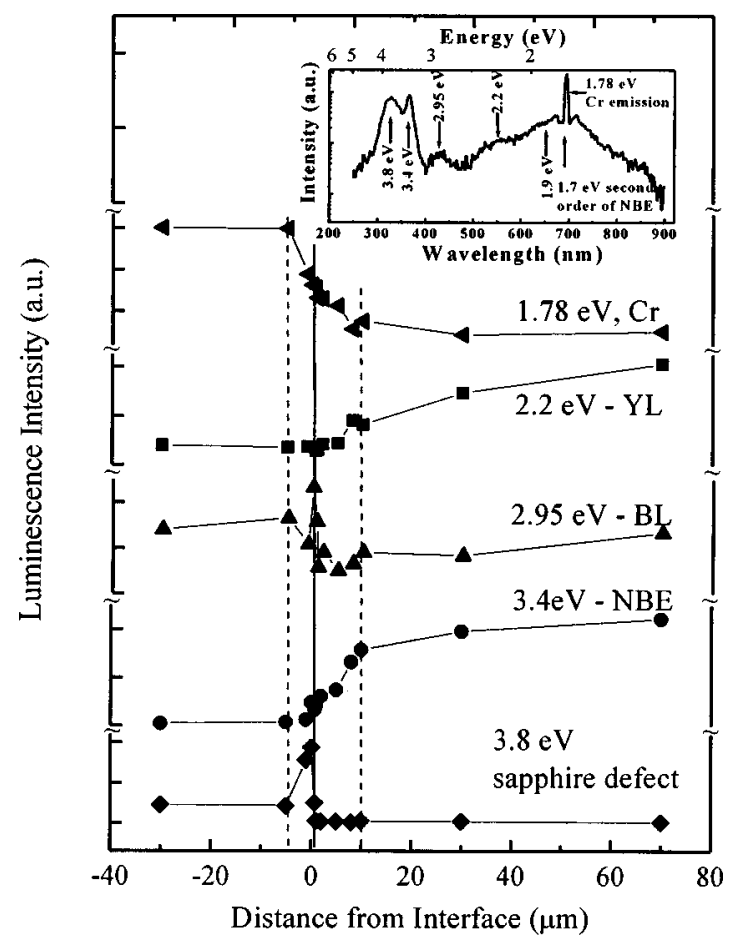

FIG. 2. CL intensity profiles for each spectral feature vs distance $d_{\text {int }}$ from the interface. The scans are not normalized to a constant value. The GaN/ sapphire interface is referenced as $d_{\text {int }}=0$. 
Fig. 2. The GaN NBE emission increases rapidly within the first $10 \mu \mathrm{m}$ from the interface into the GaN bulk, then gradually over the next $60 \mu \mathrm{m}$. The YL emission shows a more gradual increase with $d_{\text {int }}$ over the same depth range. Significantly, the absolute YL intensity and its value normalized to the GaN NBE intensity both increase while dislocation density decreases with increasing $d_{\text {int }}>10 \mu \mathrm{m}$. This result suggests that dislocations are not the source of YL in the "bulk" region as proposed elsewhere. ${ }^{16}$ The low YL intensity for $d_{\text {int }}<2 \mu \mathrm{m}$ may be due to competing recombination pathways, e.g., via impurity levels. Cr emission at $1.78 \mathrm{eV}$ from the $\mathrm{Al}_{2} \mathrm{O}_{3}$ decreases rapidly within this $d_{\text {int }}<10 \mu \mathrm{m}$. The 3.8 $\mathrm{eV}$ peak has low intensity within the $\mathrm{Al}_{2} \mathrm{O}_{3}$, increases with interface proximity, then disappears in the GaN. We argue that this peak may be due to $\mathrm{Al}-\mathrm{N}-\mathrm{O}$ complexes, since 3.8 $\mathrm{eV}$ emission in AlN has been assigned to $\mathrm{O}$ impurities. ${ }^{17} \mathrm{~A}$ similar broad emission above band edge with different energy was observed in sample $\mathrm{C}$, which will be discussed later. The broad $2.9 \mathrm{eV}$ BL intensity is negligible within the $\mathrm{Al}_{2} \mathrm{O}_{3}$ or the bulk GaN but is observed for $d_{\text {int }}<0.2 \mu \mathrm{m}$. Unlike the $2.9 \mathrm{eV}$ emission commonly reported for heavily Mg-doped $p$-type $\mathrm{GaN}$, ours appears in an $n$-type sample. Pankove et al. ${ }^{18}$ have reported broad $2.9 \mathrm{eV} \mathrm{CL}$ emission for $\mathrm{Zn}$-doped $\mathrm{GaN}$. Interfacial $\mathrm{Zn}$ might be plausible since sample A employed a $\mathrm{ZnO}$ buffer on the $\mathrm{Al}_{2} \mathrm{O}_{3}$. Such treatment can result in a $\mathrm{Zn}$-spinel structure ${ }^{19}$ and residual $\mathrm{Zn}$ impurities near the interface even though the $\mathrm{ZnO}$ was thermally desorbed prior to growth. However, other $n$-type samples not treated with Zn displayed $2.9 \mathrm{eV}$ emission at the interface. Previous work has suggested as yet unidentified point defects and impurities as an alternative explanation for this blue emission. ${ }^{20}$ More recent work provides evidence to correlate broad $\sim 2.8 \mathrm{eV}$ emission to the presence of $\mathrm{O}$, in particular a transition from a substitutional oxygen donor $\left(\mathrm{O}_{\mathrm{N}}\right)$ level to the $\mathrm{V}_{\mathrm{Ga}}-\mathrm{O}_{\mathrm{N}}$ complex acceptor. ${ }^{21}$

In order to identify the source of near-interface doping and defects, we obtained low temperature (10 K) CLS and CL images in a cross section of a $5 \mu \mathrm{m}$-thick sample $\left(\mathrm{A}_{2}, n_{\text {int }}=1.6 \times 10^{15} \mathrm{e} / \mathrm{cm}^{2}\right)$, which was also pretreated with $\mathrm{ZnO}$ buffer layer. Three spectra taken at different distances from the $\mathrm{GaN} / \mathrm{Al}_{2} \mathrm{O}_{3}$ interface of $\mathrm{A}_{2}$ are shown in Fig. 3. Since the yellow luminescence in these samples decreases strongly at low temperature to negligible levels, we present only the emissions that are near the GaN band edge. The spectra taken in the interface region $\left(d_{\text {int }}=0.3 \mu \mathrm{m}\right)$ have an extra peak above the band gap (at $3.517 \mathrm{eV}$ ), likely due to the free electron recombination band (FERB) at degenerate carrier concentrations. As the depth increases, the intensity of this line decreases $\left(d_{\mathrm{int}}=1 \mu \mathrm{m}\right)$, and the peak disappears near the surface $\left(d_{\mathrm{int}}=4 \mu \mathrm{m}\right)$. The spectra taken in the $d_{\text {int }}$ $=4 \mu \mathrm{m}$ region show strong neutral donor bound exciton $\left(D^{0} X\right)$ emission at $3.483 \mathrm{eV}$. The full width at half maximum (FWHM) of the $D^{0} X$ line is $10 \mathrm{meV}$, which indicates good crystalline quality of this sample. This line may also contain contributions from free excitons, which should have energies only about $6 \mathrm{meV}$ above those of the donor-bound excitons. A peak at $3.464 \mathrm{eV}$ is assigned to an exciton bound to an acceptor. ${ }^{22}$ An emission at or slightly above $3.503 \mathrm{eV}$ is also observed as a shoulder on the $D^{0} X$ line. The actual peak

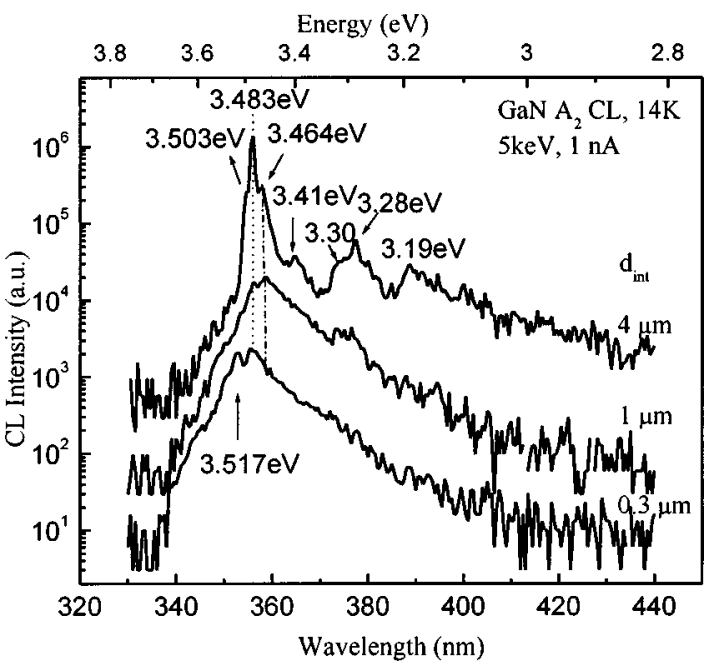

FIG. 3. CL spectra of sample $\mathrm{A}_{2}$ acquired at $d_{\text {int }}=0.3,1$, and $4 \mu \mathrm{m}$ as shown. Near-interface features differ strongly from those of the bulk.

energy may be higher than $3.503 \mathrm{eV}$, perhaps close (assuming an exciton binding energy of $26.4 \mathrm{meV})^{23}$ to the expected free-exciton excited-state energy in this sample of about $3.509 \mathrm{eV}$ [i.e., $3.483+0.006+\frac{3}{4}(0.0264) \mathrm{eV}$ ].

The CL spectra at different depths also indicate that the quality of the GaN epitaxial layer improves when the film gets thicker. However, as the $d_{\text {int }}$ increases away from the interface, four additional optical transitions at 3.41, 3.30, 3.28 , and $3.19 \mathrm{eV}$ appear. The peaks at 3.28 and $3.19 \mathrm{eV}$ are the characteristic neutral donor-acceptor pair recombination $\left(D^{0} A^{0}\right)$ and its LO phonon replica $\left(D^{0} A^{0}\right.$-LO) in the GaN bulk.

In order to understand the spatial dependence and physical nature of these peaks, we further obtained monochromatic CL images in the whole cross section of this sample at $10 \mathrm{~K}$. Figure 4 shows the SEM image and the monochromatic spatial maps of some different peaks as indicated in Fig. 3. In the SEM image as shown in Fig. 4(a), the small triangle area at the lower right corresponds to the sapphire substrate, whereas the triangular region at the upper left corresponds to the free GaN surface. The arrow in each image indicates the interface. The CL image areas in Figs. 4(b) and 4(c) correspond to the same region as the SEM image. The monochromatic images display spatial variations in peak intensities at (b) $3.483 \mathrm{eV}$ and (c) $3.30 \mathrm{eV}$. Textured regions within these images serve to indicate the brighter emitting areas. The luminescence intensities of some CLS peaks are weak, not well resolved, and consequently not shown here. Similarities between features within images provide an indication of optical transitions with common physical origins. However, the intensity contributions of adjacent spectral features can complicate these spatial correlations and differences between defect distributions.

Temperature-dependent $(10-300 \mathrm{~K})$ experiments provide additional clues to the origins of the emissions as shown in Figs. 3 and 4. Figure 5 shows the temperature-dependent spectra taken from the bulk epilayer $\left(d_{\text {int }}=4 \mu \mathrm{m}\right)$. The energy of the four emissions shown all decrease with increased temperature and change at different rates. Figure 6(a) is an 

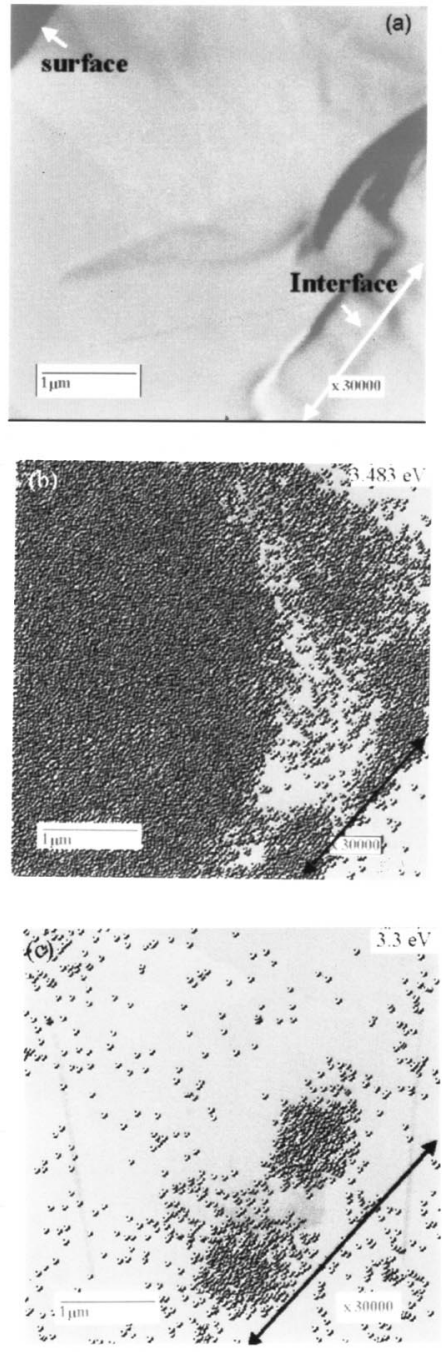

FIG. 4. (a) SEM image and CL images shown for emissions of (b) $3.483 \mathrm{eV}$ and (c) $3.30 \mathrm{eV}$ acquired within the cross section of sample $\mathrm{A}_{2}$. The length scales are the same as in (a). The arrow in each CL image indicates the $\mathrm{GaN} / \mathrm{sapphire}$ interface, and the numbered spots indicate where spectra were acquired.

Arrhenius plot of the integrated intensities of the $D^{0} X$ peak at $3.483 \mathrm{eV}$, the $3.41-\mathrm{eV}$ peak, and the $3.30 \mathrm{eV}$ peak. Figure 6(b) gives the temperature dependence of their optical transition energies corresponding to Fig. 5.

The data for low $N_{\text {int }}$ presented in Figs. 3-6 provide evidence for several near-interface phenomena. As Fig. 6(a) shows, the peak at $3.483 \mathrm{eV}$ quenches first with an energy of $4 \mathrm{meV}$, then $12 \mathrm{meV}$ at higher temperatures, presumably due to two competitive recombination channels. The small energy quenching of the $D^{0} X$ corresponds to the thermal detrapping of exciton from the shallow donor $(\sim 6 \mathrm{meV})$ while the second nonradiative path could be ionization of the neutral donor involved in the excitonic complex. ${ }^{24}$ These activation energies should be viewed with caution since CL intensities are affected by spectral overlap and temperaturedependent broadening.

At low temperature, the $3.41 \mathrm{eV}$ is sharp and intense, indicating its excitonic nature. As temperature increases, the $3.41-\mathrm{eV}$ peak in Fig. 5 becomes more pronounced and

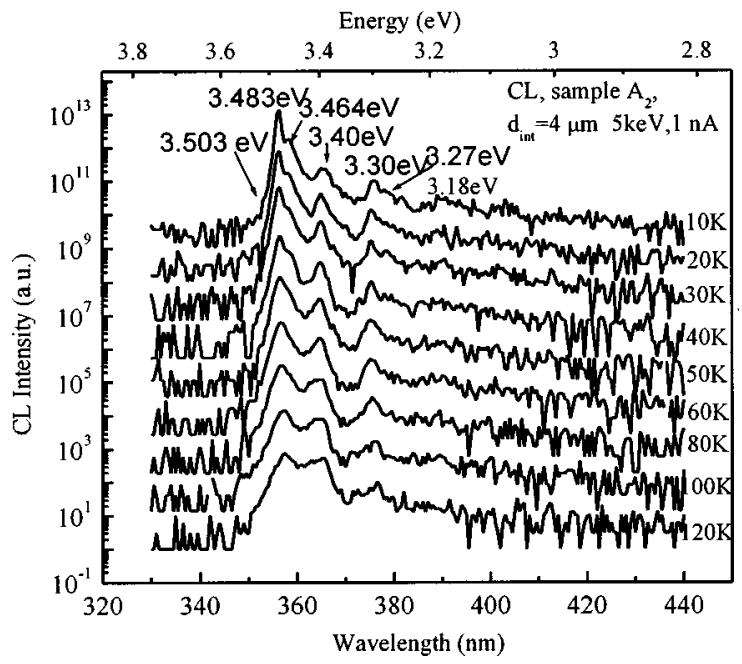

FIG. 5. Temperature dependence of the luminescence spectra of sample $\mathrm{A}_{2}$ showing temperature quenching behaviors of each emission.

quenches very slowly. The activation energy shown in Fig. 6(a) for quenching is only $7 \mathrm{meV}$, which is lower than the activation energy for this $3.41 \mathrm{eV}$ band reported by Leroux, ${ }^{30}$ varying between 12 and $40 \mathrm{meV}$. This is because the 3.40 peak can be mixed with the LO phonon replica of the DX peak since the relative contribution of the latter increases
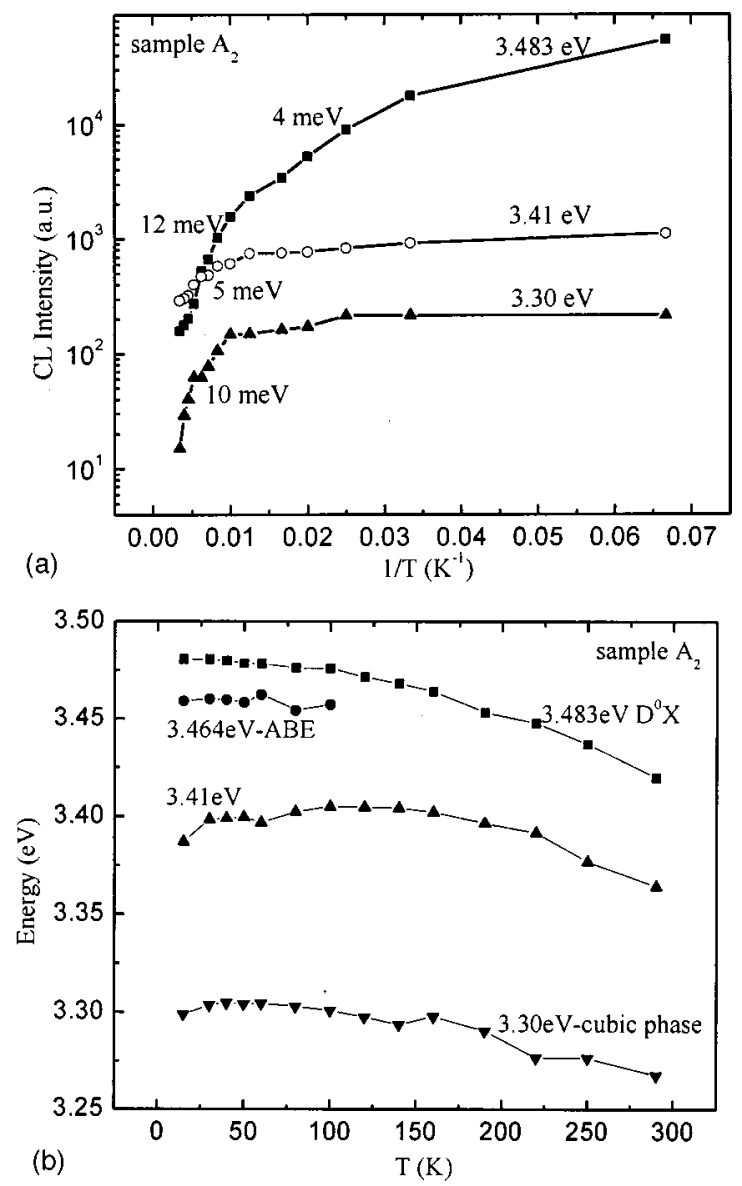

FIG. 6. (a) Temperature dependence of the $3.483,3.41$, and $3.30 \mathrm{eV}$ peak intensities in Fig. 5 and (b) temperature dependence of their energies, including the $3.464 \mathrm{eV}$ peak. 
with temperature. A model ${ }^{25}$ has been proposed for this frequently reported emission ${ }^{26,27,28}$ based on recombination of an exciton bound to an $I_{1}$ type stacking fault in $\mathrm{GaN}$. In this model, the stacking fault is similar to a cubic quantum well in wurtzite GaN. The electrons are trapped by the stacking fault and holes in the wurtzite matrix type II quantum well. Calleja et al. ${ }^{29}$ reported a broad emission centered at $3.41 \mathrm{eV}$ and attributed it to structural defects at the column/substrate interface. Combining these two models, it is not unexpected that stacking faults appear at the column/substrate interface where high density defects concentrate.

All the quenching energies reported here are lower than those of the MOCVD samples measured by photoluminescence (PL) reported by Leroux et al. ${ }^{30}$ In that work, the activation energies reported for $D^{0} X$ were $5-7 \mathrm{meV}$ at low temperatures and $34-36 \mathrm{meV}$ at higher temperatures, while the activation value for the $3.41 \mathrm{eV}$ peak was $12 \mathrm{meV}$. The small value of the activation energy is probably caused by overlap and temperature-related broadening of the peaks.

The $3.30-\mathrm{eV}$ peak is most prominent at $d_{\text {int }}$ $=1-1.5 \mu \mathrm{m}$ as shown in Fig. 4(c) and may be indicative of another phase besides wurtzite $\mathrm{GaN}$ in this region. As shown in Fig. 6(a), the 3.30-eV peak quenches with an energy of 10 $\mathrm{meV}$, versus $5 \mathrm{meV}$ for the $3.41 \mathrm{eV}$ peak at low temperatures. Furthermore, there appear to be no phonon replicas increasing with increasing temperature in Fig. 5. Hence the $3.30 \mathrm{eV}$ peak is not likely to be a phonon replica of the 3.41 $\mathrm{eV}$ peak. Instead, we believe it is related to a second phase. From its energy, it could be due to either $\mathrm{ZnO}$ or cubic phase $\mathrm{GaN}$ domains that often coexist with the hexagonal phase. Considering that this sample was treated with a $\mathrm{ZnO}$ buffer layer, a $\mathrm{ZnO}$ phase is not unexpected close to the interface. Since secondary mass ion spectroscopy (SIMS) shows no $\mathrm{Zn}$ in the samples, this peak is more likely to be a cubic domain, since stacking faults are cubic in nature.

Finally, the low $N_{\text {int }} \mathrm{A}_{2}$ specimen data show evidence for near-interface free carriers. As shown in Fig. 3, a shoulder appears above the excited state emission line, increasing in intensity for decreasing distance from the interface. In the spectra taken near the interface $\left(d_{\text {int }}=0.3 \mu \mathrm{m}\right)$, this structure peaking at about $3.517 \mathrm{eV}$ is well resolved. This peak may be due to band-to-band transitions, since the free-carrier concentration in this near interface range is usually high. ${ }^{10,31}$

\section{MIDLEVEL SHEET CARRIER CONCENTRATION}

Samples with higher $N_{\text {int }}$ provide an opportunity to identify the source of the residual near-interface doping. We have carried out low temperature (10 K) CLS as a function of $d_{\text {int }}$ of HVPE grown $\mathrm{GaN} / \mathrm{Al}_{2} \mathrm{O}_{3}$ with carrier concentration $N_{\text {int }}$ $=9.8 \times 10^{15} \mathrm{e} / \mathrm{cm}^{2}$ (sample B). CLS, CL imaging, and SIMS data of unintentionally doped $\mathrm{GaN}$ samples provide information at the interface. Sample B was not grown on a $\mathrm{ZnO}$ buffer layer. The depth profile CLS in Fig. 7 exhibits the typical sharp features found in GaN, including the $D^{0} X$ transitions at 3.473-3.485 eV. For distances $>1 \mu \mathrm{m}$, an extra peak appears at $3.388 \mathrm{eV}$, ascribed to the phonon replica of the $D^{0} X{ }^{30}$ Another dominant feature in these spectra corresponds to neutral donor-acceptor-pair $\left(D^{0} A^{0}\right)$ transitions at

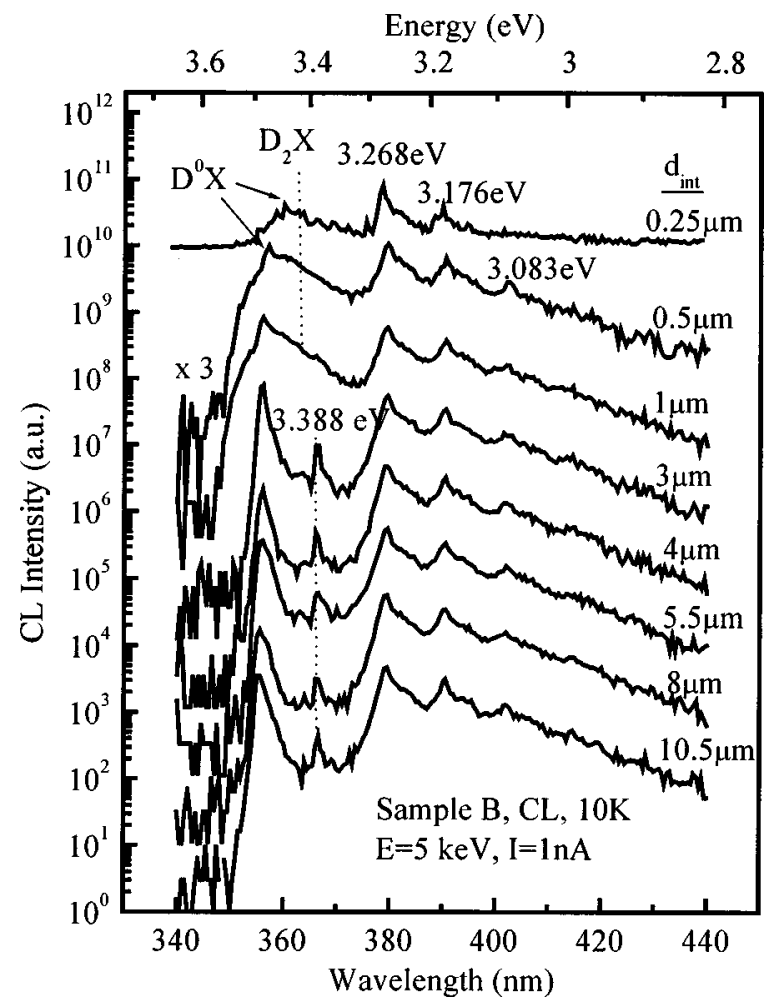

FIG. 7. Low temperature CL spectra as a function of distance from the interface. Features above and below the DX transition energy differ significantly between the interface and the bulk.

3.2 to $3.3 \mathrm{eV}$, followed by a sequence of longitudinal optical phonon replicas $(\Delta h \nu=92$ to $93 \mathrm{meV})$. The dominant acceptor may either be $\mathrm{C},{ }^{32}$ detected by SIMS in similar samples, ${ }^{33,34}$ or the Ga vacancy, detected by positron annihilation. ${ }^{34}$ However, it is not likely $\mathrm{Mg}$, which is not detected by SIMS. ${ }^{33}$ These features are common to GaN at all depths. However, near the interface, i.e., at $d_{\text {int }} \leqslant 1 \mu \mathrm{m}$, an additional feature appears at $3.447 \mathrm{eV}$, somewhat broader than the $D^{0} X$ peak.

Figure 8 shows the SEM image of sample B along with monochromatic CL images taken at $10 \mathrm{~K}$. CL images are shown for (b) $3.483 \mathrm{eV}$ due to $D^{0} X$ luminescence and (c) $3.28 \mathrm{eV}$ due to $D^{0} A^{0}$ transitions. The emission of $D^{0} X$ fluctuates in intensity, whereas the emissions of $D^{0} A^{0}$ are dominant and quite uniform. Figure 9 illustrates the temperaturedependent CL spectra of sample B taken at $d_{\text {int }}=3 \mu \mathrm{m}$, showing the $D X, D^{0} A^{0}$, and phonon replicas.

The data for intermediate $N_{\text {int }}$ presented in Figs. 7-9 illustrate significant changes from the bulk to the nearinterface region. The depth dependent CL spectra show that at $d_{\text {int }}>1 \mu \mathrm{m}, D^{0} X$ has a blueshift to $3.483 \mathrm{eV}$, which is probably due to a reduction in band tailing. An important feature in the near interface region is the broadening of the exciton peaks. As $d_{\text {int }}$ increases, the FWHM of the $D^{0} X$ and $D^{0} A^{0}$ transitions become narrower, showing that the crystalline quality of the sample improves with distance away from the interface, up to $d_{\text {int }}=3 \mu \mathrm{m}$.

An additional feature at $3.447 \mathrm{eV}$, appearing near the interface, arises from the degenerate doping. A broad structure is not unexpected in the highly degenerate region, due to 

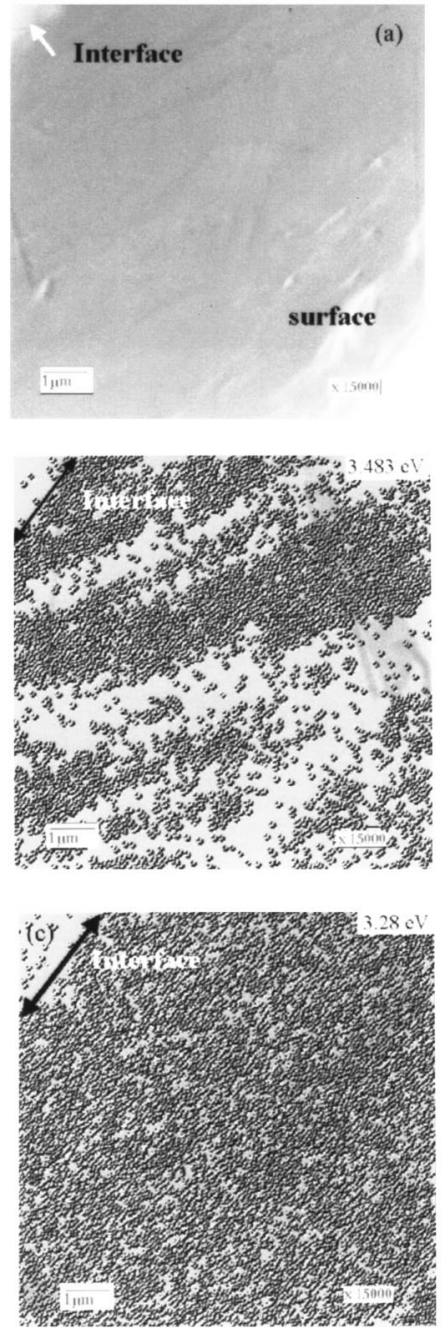

FIG. 8. Sample B SEM image in (a) and CL images for emissions in cross section at $3.483 \mathrm{eV}$ in (b), and $3.28 \mathrm{eV}$ in (c). The length scales are those shown in the SEM image. The arrow in each CL image indicates the GaN/ sapphire interface.

band tailing and band filling (Moss-Burstein) effects or less than perfect crystal quality. However, the $3.447 \mathrm{eV}$ peak may also be a two-electron replica of the $D^{0} X$ line, ${ }^{30}$ because such a line would be expected at $3.473 \mathrm{eV}-(3 / 4) E_{D}$, where $E_{D}$ should be about $30 \mathrm{meV}$. That is, the final state of the $3.473 \mathrm{eV}$ transition is the ground state $(n=1)$ of the donor, whereas the $3.447 \mathrm{eV}$ transition would then have an $n=2$ final state. But if this latter model were correct, then the two transitions might be expected to have about the same linewidth and the ratio between the two peaks should be more constant at the chosen temperature. However, besides the change in linewidth apparent in Fig. 7, this figure also shows that this ratio changes considerably at different depths. This behavior is therefore not consistent with a two-electron replica.

Another possibility for the $3.447-\mathrm{eV}$ transition is an exciton bound to a deep donor or acceptor. If the Haynes factor is 0.1 to $0.2,{ }^{35}$ then this deep center would have an energy of about $150-300 \mathrm{meV}$ from a band edge. An acceptor-bound exciton would be the most likely candidate, since acceptor centers are clearly evident from the strong $D^{0} A^{0}$ transitions.

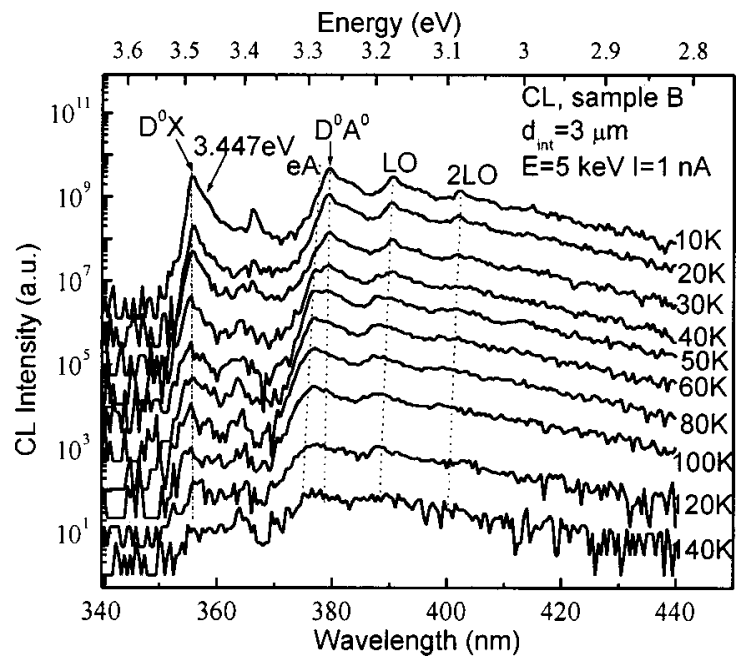

FIG. 9. Temperature dependence of the $D X, D^{0} A^{0}$, and phonon replica peak luminescence features of sample B.

Of all possible acceptors, only the Ga vacancy would have a high enough concentration, i.e., from positron annihilation spectroscopy (PAS), $\left[\mathrm{V}_{\mathrm{Ga}}\right]=10^{17}$ to $10^{18} \mathrm{~cm}^{-3}$ in a MOCVD GaN epilayer, ${ }^{36}$ or even $>10^{19} \mathrm{~cm}^{-3}$ in HVPE GaN materials. ${ }^{34}$ However, PAS in conjunction with Hall measurements show that $\mathrm{V}_{\mathrm{Ga}}$ is the dominant acceptor everywhere, both in the interface and bulk regions, ${ }^{34}$ while the $3.447 \mathrm{eV}$ emission is only evident near the interface. Therefore the depth-dependent CLS results argue against assignment of this feature to Ga vacancies.

With regard to donors, $\mathrm{Si}$ and $\mathrm{O}$ are believed to induce a shallow donor state with a binding energy of 31 and 34-35 $\mathrm{meV}$, respectively. ${ }^{37}$ The only donor with a high enough concentration to give the observed strong intensity of the 3.447 $\mathrm{eV}$ peak near the interface is $\mathrm{O}$, because $\mathrm{O}$ concentration increases strongly near the interface, whereas the concentration of Si does not. ${ }^{34}$ Figure 10 shows SIMS measurements of this specimen performed at Chas. Evans and Associates. ${ }^{33}$ The SIMS plot displays concentrations as high as 7 $\times 10^{19} \mathrm{~cm}^{-3}$ near the interface, decreasing to mid-

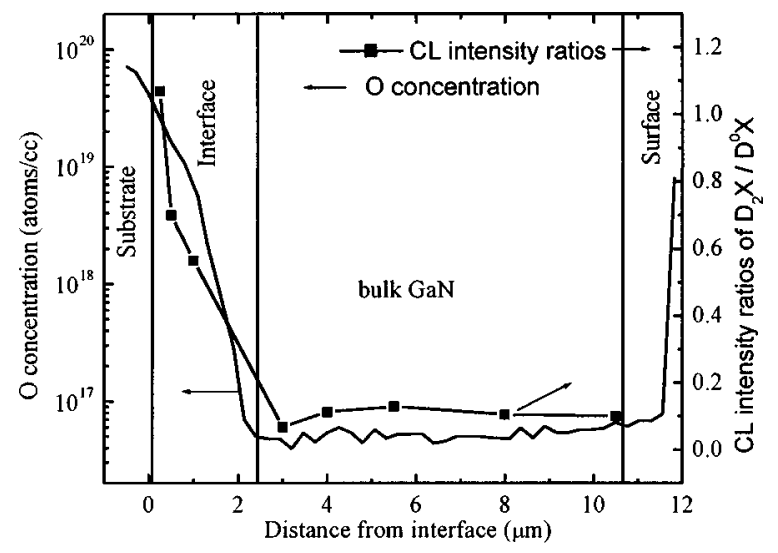

FIG. 10. O profiles near the interface detected by SIMS compared with the luminescence intensity of the $3.447 \mathrm{eV}$ peak relative to the $D^{0} X$ near band edge emission. The clear similarity in depth dependence demonstrates that $\mathrm{O}$ diffusion from the sapphire is correlated with the $3.447 \mathrm{eV}$ donor level. 
$10^{18} \mathrm{~cm}^{-3}$ over a distance range $d_{\text {int }} \leqslant 1 \mu \mathrm{m}$. Similarly, the ratio of the $3.447 \mathrm{eV}$ transition (termed $D_{2} X$ ) relative to the $D^{0} X$ near band edge emissions is highest at the interface and decreases steadily with distance over the same $2 \mu \mathrm{m}$ into the $\mathrm{GaN}$. Significantly, Si and C impurity concentrations in this interface region are several orders of magnitude smaller and exhibit no strong variation with depth. ${ }^{33}$ No other donor impurity is localized in this depth range. Electron concentration $n_{\text {int }}$ (measured by ECV) is also extremely high in the interface region. Here again, the comparison of carrier concentrations versus depth reveals a close correspondence between a shallow donor and $\mathrm{O}^{34}$ This agreement between optical, chemical, and electrical features indicates that electron donors in the interface region must come mainly from O. Furthermore, this identification is consistent with the assignment of interface-localized blue ( 2.8 to 2.9 ) eV luminescence in $n$-type $\mathrm{GaN}$ to $\mathrm{O}$ donor-related complexes, as discussed in Sec. III. Overall, the close correlation between CLS spectral peak intensities with [O] spatial distribution indicates that $\mathrm{O}$ impurities diffused from the $\mathrm{Al}_{2} \mathrm{O}_{3}$ are the origin of the high sheet carrier concentration.

At low temperature, the $\mathrm{CL}$ is dominated by neutral donor bound exciton $\left(D^{0} X\right)$ transitions. With increasing temperature, Fig. 9 shows that the $A$ free exciton line increases as the $D^{0} X$ peak quenches. Other features appearing in the spectra are $D^{0} A^{0}$ lines near $3.27 \mathrm{eV}$ and their $\mathrm{LO}$ and $2 \mathrm{LO}$ phonon replicas near 3.18 and $3.09 \mathrm{eV}$, respectively. These involve the usual residual acceptor, possibly carbon or the Ga vacancy as described before. As temperature increases, the $D^{0} A^{0}$ emission is replaced by band-acceptor $(e A)$ emission. The latter can be distinguished from the former since it shifts to higher energy with increasing temperature. Figure 9 shows that the energy difference between $D A$ and $e A$ transitions is $23 \mathrm{meV}$ and is in principle a measure of the background donor binding energy. We neglect the Coulomb correction in this simple approach. Including this correction effectively increases the donor binding energy. Figure 9 shows a shoulder appearing on the lower energy side of both $D^{0} X$ and $D^{0} A^{0}$ emissions. These shoulders may be related to coupling with other than LO phonons. As shown in the CL image of $D^{0} X$ in Fig. 8(b), the edge emission fluctuates in intensity and is weak at grain boundaries, i.e., in the regions of high defect density. It is likely that these regions with high defect density play a role in trapping impurities.

\section{HIGH SHEET CARRIER CONCENTRATION}

In this section we discuss the behavior of optical transitions in a $17 \mu \mathrm{m}-\mathrm{GaN}$ sample (sample $\mathrm{C}$ ) with the highest relative $N_{\text {int }}\left(5.0 \times 10^{16} \mathrm{e} / \mathrm{cm}^{2}\right)$. Here the sapphire substrate was nitrided prior to deposition by exposure to $\mathrm{NH}_{3}$. Figure 11 illustrates low temperature $(10 \mathrm{~K}) \mathrm{CLS}$ as a function of $d_{\text {int }}$, analogous to Figs. 3 and 7. The depth-dependent CLS in Fig. 11 exhibits a broadband above the band edge emission as $d_{\text {int }} \leqslant 5 \mu \mathrm{m}$, labeled as $X_{1}$. As the depth increases, the spectrum is dominated by $D^{0} X$ at $3.483 \mathrm{eV}$. The FWHM also decreases with thickness increasing, and the FWHM of the strongest $D^{0} X$ at $d_{\text {int }}=10 \mu \mathrm{m}$ is $15 \mathrm{meV}$, showing that this sample has good crystal quality. For distance $d_{\text {int }}$

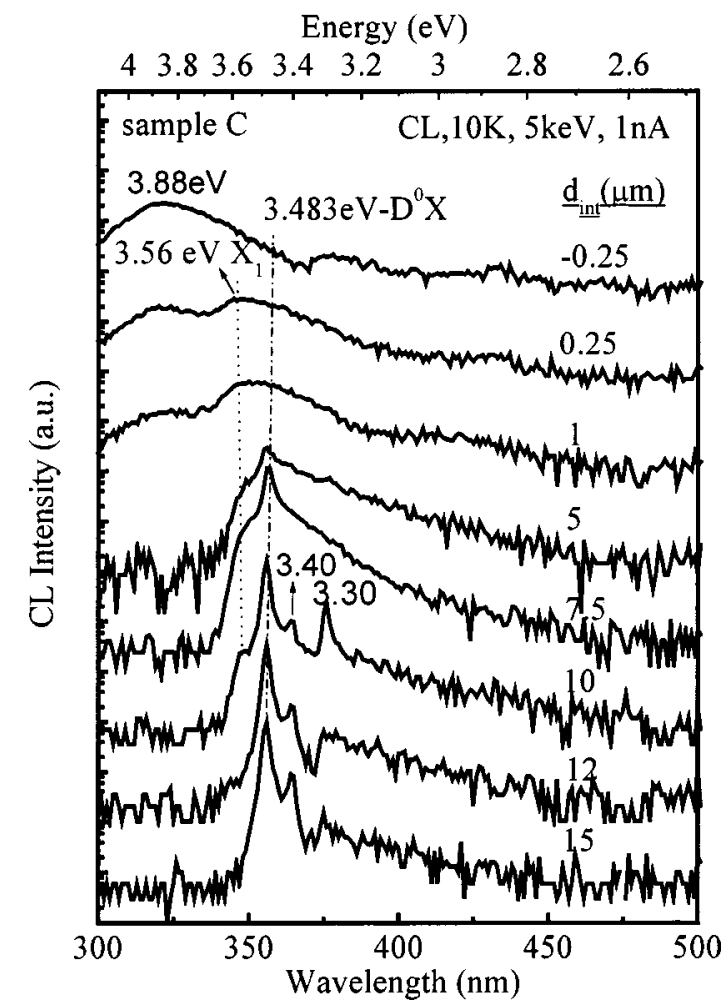

FIG. 11. Low temperature depth profile CL spectra of sample C showing emissions at $3.56,3.483,3.40$, and $3.30 \mathrm{eV}$.

$\geqslant 10 \mu \mathrm{m}$, two extra peaks at 3.40 and $3.30 \mathrm{eV}$ become prominent. They are ascribed to excitons bound to stacking faults and a cubic GaN domain, respectively, as discussed in Sec. III.

We also obtained monochromatic spatial maps of the emission intensities for different spectral features within the cross sectional structure. Figure 12 shows the SEM image (a) and the monochromatic spatial maps of different peaks at (b) $3.563 \mathrm{eV}$, (c) $3.483 \mathrm{eV}$, (d) $3.40 \mathrm{eV}$, and (e) $3.30 \mathrm{eV}$. In the SEM image, the small triangular area at the lower right corresponds to the sapphire substrate, whereas the line at the upper left indicates the free GaN surface. CL images were recorded from the same region as that shown in the SEM image. Enhanced image contrast and brightness serve to highlight emitting areas and enhance comparison of features from image to image.

As shown in Fig. 11, a broadband at $3.88 \mathrm{eV}$ appears at $d_{\text {int }} \leqslant 1 \mu \mathrm{m}$. Just as with the $3.8-\mathrm{eV}$ (at room temperature) peak in sample $A_{1}$, this feature has high intensity near the $\mathrm{GaN} / \mathrm{Al}_{2} \mathrm{O}_{3}$ interface $\left(d_{\text {int }}=-0.25-0.25 \mu \mathrm{m}\right)$, but decreases into the GaN bulk. Unlike impurity band filling even for impurity concentrations $>10^{20} \mathrm{~cm}^{-3}$, this peak is centered well above the conduction band edge and due to an amorphous $\mathrm{Al}-\mathrm{N}-\mathrm{O}$ complex. This is consistent with the increasing in peak intensity with proximity to the interface.

As shown in Fig. 11, the energy and width of the broadband $X_{1}$ changes with the thickness of the epilayer, particularly at the interface $\left(d_{\text {int }} \leqslant 1 \mu \mathrm{m}\right)$, where a broad feature centered at $3.56 \mathrm{eV}$ appears. These spectra are typical of a highly doped material with an electron concentration of about $10^{19} \mathrm{~cm}^{-3}$ based on the model proposed by 

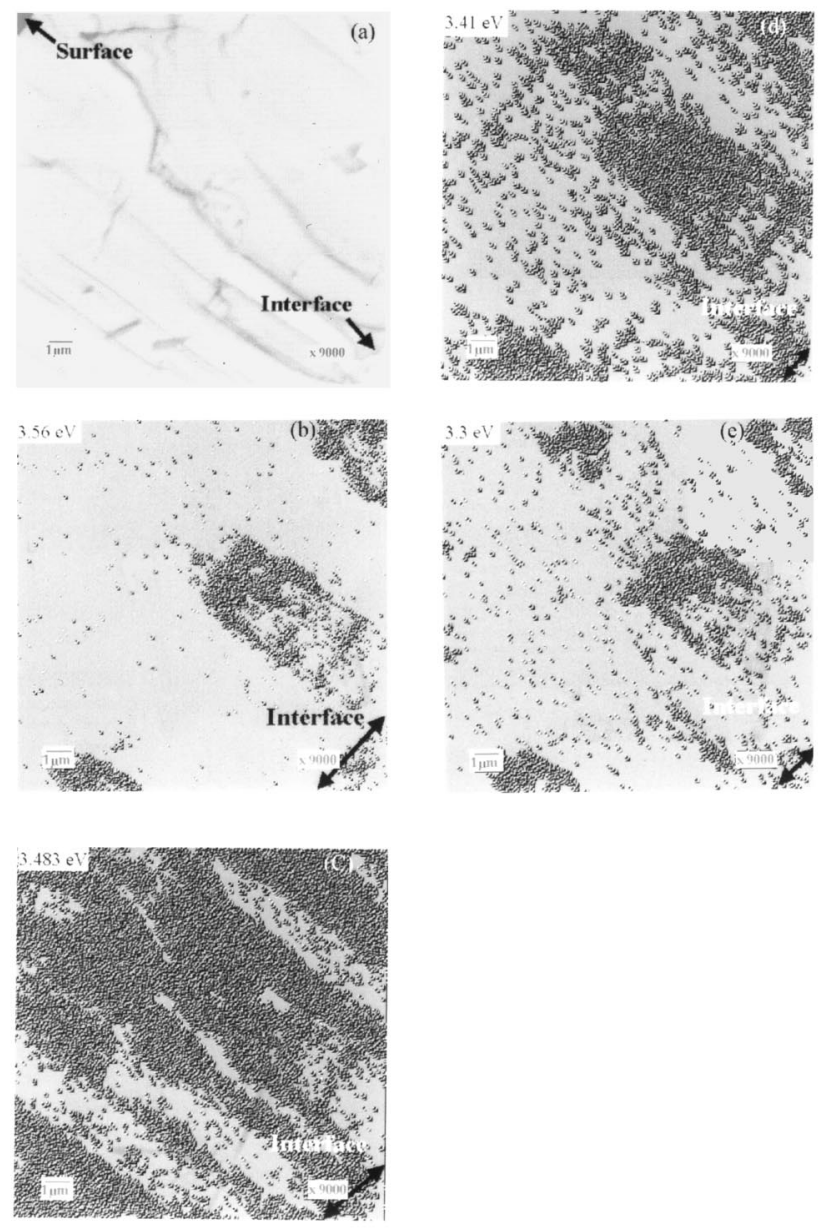

FIG. 12. (a) SEM image and CL images for emissions at (b) $3.56 \mathrm{eV}$, (c) $3.483 \mathrm{eV}$, (d) $3.41 \mathrm{eV}$, and (e) $3.30 \mathrm{eV}$. The length scales are all the same as that shown in the SEM image, and the arrow in each CL image indicates the GaN/sapphire interface.

Arnaudov. ${ }^{38}$ The possible explanations for this broadening to higher energies are band filling at these degenerate doping levels, and the free-electron recombination across the band gap. $^{38}$ The energy of this broad emission extends to $3.6 \mathrm{eV}$, also possibly due to Al-GaN alloy. Such NBE corresponding to $\mathrm{Al}_{x} \mathrm{Ga}_{1-x} \mathrm{~N}$ alloying has been previously observed at $\mathrm{Al}-$ GaN interfaces. ${ }^{39}$ Pregrowth nitridation of sapphire for such specimens should further enhance Al-N bonding and alloying. ${ }^{40}$ For samples nitrided inside the HVPE reactor at high temperature, a thin AlN layer is not unexpected, given the reaction:

$$
\mathrm{Al}_{2} \mathrm{O}_{3}+2 \mathrm{NH}_{3} \Rightarrow 2 \mathrm{AIN}+3 \mathrm{H}_{2} \mathrm{O} \text {. }
$$

The formation of AlN islands as a result of a high temperature $\mathrm{NH}_{3}$ exposure has also been reported in the literature. ${ }^{40,41}$ This high temperature environment may also lead to desorption of $\mathrm{H}_{2} \mathrm{O}$ and $\mathrm{O}$ impurities near the interface.

The image of the band edge CL emission $(3.483 \mathrm{eV})$ as shown in Fig. 12(c) indicates spatial striations in intensity, indicative of columnar structure. The decrease in $D^{0} X$ emission intensity between these columnar regions may be due to grain boundaries, i.e., regions of high defect density, which can act as efficient centers of nonradiative recombination. Therefore edge emission is expected to quench at grain boundaries. The CL images in Fig. 12(b) show that the $X_{1}$ peak at $3.56 \mathrm{eV}$ appears in the same spatially localized regions as the 3.41 and $3.30 \mathrm{eV}$ emissions. All three display high intensity primarily in three spatial regions. Interestingly, these high carrier concentration regions appear to extend along columns a significant distance from the interface. We attribute the $3.41 \mathrm{eV}$ emission to an exciton bound to stacking faults. ${ }^{25}$ Significantly, the $3.30 \mathrm{eV}$ emission related to cubic zinc-blende phase GaN appears in almost the same regions as the $3.41 \mathrm{eV}$ emission. This is not surprising since stacking faults are known to give rise to zinc-blende GaN. It appears from Fig. 12 that such new phase formation is associated with highly doped areas. The short-range order of wurtzite and zinc-blende $\mathrm{GaN}$ structures is virtually identical, however, the stacking sequence of atom arrangement in closed-packed planes is different, i.e., $\cdots A a B b A a B b A a B b \cdots$ for the wurtzite, and $\cdots A a B b C c A a B b C c \cdots$ for the zinc blende. A fault in the stacking sequence transforms one structure into the other, hence the respective stacking fault energy corresponds to the free energy difference between the wurtzite and zinc-blende modifications. As a consequence, the density of such structural defects is expected to be high in nitrides exhibiting a low energy difference between these phases. ${ }^{42}$ Similar phenomena were also observed in cubic GaN. ${ }^{43}$ The high defect density may be responsible for the high doping density since $\mathrm{O}$ can probably diffuse more rapidly in highly defective regions.

\section{DISCUSSION}

Depth-dependent CLS and CL images provide new information for detecting the location and physical origin of defects and impurity doping at $\mathrm{GaN} / \mathrm{Al}_{2} \mathrm{O}_{3}$ interfaces. Temperature-dependent CLS also aid in identifying the various transitions observed in GaN epilayers grown on sapphire substrates. Impurity state densities depend strongly on substrate chemical and thermal treatments. Figure 13 shows CL spectra of three samples $\left(\mathrm{A}_{2}: 5 \mu \mathrm{m}, \mathrm{B}: 11 \mu \mathrm{m}\right.$, and $\mathrm{C}: 17$ $\mu \mathrm{m}$ ) (a) near interface and (b) at bulk regions. The $d_{\text {int }}$ for each spectrum is indicated in the figure. As shown in Fig. 13(b), all three samples that we investigated at low temperature display strong donor bound exciton emission in bulk regions at $10 \mathrm{~K}$. We show the depth-profile CLS of these three samples in Figs. 3, 7, and 11. The FWHM values of the $D^{0} X$ transitions become narrower as the samples get thicker, indicative of improved crystal quality. Such variations reflect the material's inhomogeneity, which is common for GaN epilayers on sapphire. Free excitons were observed in both sample $A_{2}$ and $B$, but not in sample $C$, indicative of higher quality in the former. This finding is in good agreement with ECV results. As indicated in Fig. 13, $n_{\text {int }}$ increases with increasing specimen thickness. As Figs. 13(a) and 13(b) show, FERB can be only observed near the interface region in samples $\mathrm{A}_{2}$ and $\mathrm{B}$, which have lower sheet carrier concentration and are thinner. However, in sample $\mathrm{C}$, the emission from FERB increases and extends further into the bulk re- 

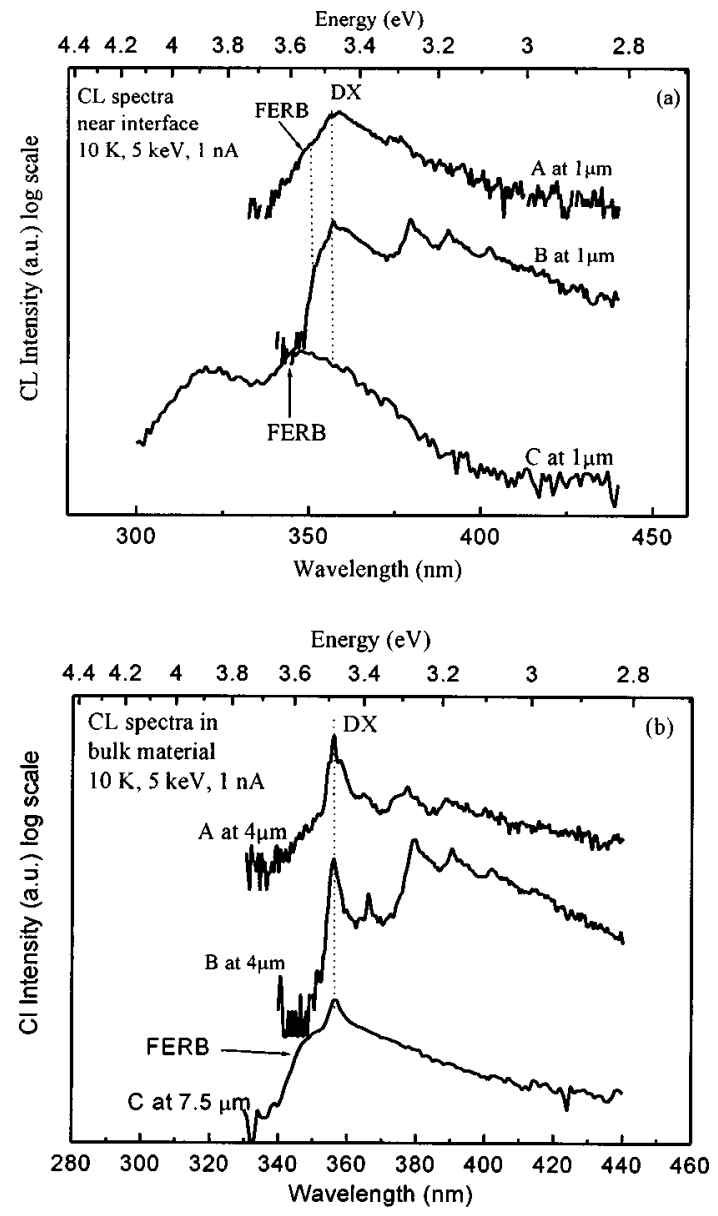

FIG. 13. HVPE GaN/ $/ \mathrm{Al}_{2} \mathrm{O}_{3}$ CL near-interface spectra. Band tailing, band filling, and possible alloying are evident at higher sheet carrier concentration.

gion. It indicates that impurity diffusion for thicker specimens may extend further from the interface, i.e., to $d_{\text {int }}$ $>10 \mu \mathrm{m}$ for sample C. Such extended impurity diffusion is most evident for this thickest sample (C), consistent with its longest time at elevated growth temperature.

We observe various optical transitions related to defects, impurities, and a secondary phase in the cross section of each sample. Sample $\mathrm{A}_{2}$, with a $\mathrm{ZnO}$ buffer layer, has lower sheet carrier concentration, displaying weak residual acceptor related luminescence. The residual acceptor can either be $\mathrm{Zn}$ or C. This sample also shows excitonic emission bound to stacking faults and cubic phase $\mathrm{GaN}$. There is no evidence showing the formation of $\mathrm{Al}-\mathrm{N}-\mathrm{O}$ near the interface in this sample. However, in a $70-\mu \mathrm{m}$ sample $\left(\mathrm{A}_{1}\right)$, grown under similar growth conditions as those of $\mathrm{A}_{2}$, a broad emission was observed well above the band edge at $3.8 \mathrm{eV}$ at room temperature near the interface. We argue that this is due to a defect complex, analogous to the O impurity in AlN. ${ }^{39}$ Differences in the $3.8 \mathrm{eV}$ emission intensities may be due to different times at elevated growth temperatures, during which $\mathrm{Al}, \mathrm{O}$, and N interdiffusion could occur. Since growth rates are comparable, thicker samples held at elevated temperatures the longest might be expected to exhibit such diffusion the most. The $3.8 \mathrm{eV}$ peak emission intensity for specimen $\mathrm{C}$ relative to those of $\mathrm{A}$ and $\mathrm{B}$ is consistent with this trend, although the limited data here preclude any general correlation.

The sample with medium $n_{\text {int }}$ (sample B) shows strong emissions attributed to residual acceptors. The acceptor can be due either to $\mathrm{C}$ or the Ga vacancy, since there is no $\mathrm{Zn}$ or $\mathrm{Mg}$ found by SIMS. A new donor level at $3.447 \mathrm{eV}$ appears at the GaN/sapphire interfaces whose energy and spatial extent correlate strongly with $\mathrm{O}$ outdiffusion. The intensity of this peak is in good agreement with the $\mathrm{O}$ distribution, as evidenced by SIMS. Our results show that the source of $\mathrm{O}$ is the $\mathrm{Al}_{2} \mathrm{O}_{3}$ substrate since the $\mathrm{O}$ distribution is highest near the interface. Oxygen, not necessarily localized in the interface region, can also be due to the growth environment since a high acceptor density is also observed in this sample.

Sample C displays a large-scale columnar structure, in agreement with the observations of Paskova et al. ${ }^{22}$ The NBE emission quenches near the interface and grain boundaries where very high defect densities appear. A broad emission band at $3.56 \mathrm{eV}$ likely due to FERB was observed, showing high degenerate doping near interface and grain boundaries. $\mathrm{Al}-\mathrm{N}$ bonding is not unexpected, given the $\mathrm{O}$ release from $\mathrm{Al}_{2} \mathrm{O}_{3}$ at the atomic-scale interface. ${ }^{17}$ It is not surprising that stacking faults and zinc-blende $\mathrm{GaN}$ are formed in these highly doped areas. Together with this degenerate doping, $\mathrm{Al}-\mathrm{N}-\mathrm{O}$ complexes form near the interface of this high $N_{\text {int }}$ sample as well.

\section{CONCLUSIONS}

CL imaging and temperature-dependent CLS show systematic variations in defect emissions with a wide range of HVPE GaN/sapphire electronic properties. We report large differences between interface and bulk in terms of band edge and deep level emission. These emissions correspond to regions of high carrier concentration, impurity doping, and new phase formation. We observe interface features indicating a new donor level involving $\mathrm{O}$ impurities that can account for SIMS and ECV results. Highly degenerate interface regions give rise to above band-gap emissions due to band filling and possible alloy formation. Combined with the cross sectional SEM and CL images of the defects, the spatial data provide new information on the nature of impurity diffusion and doping at the $\mathrm{GaN} / \mathrm{Al}_{2} \mathrm{O}_{3}$ interface.

\section{ACKNOWLEDGMENTS}

This work was supported by the Office of Naval Research, the National Science Foundation, the Air Force Office of Scientific Research, and the Department of Energy (depth-dependent measurements). The authors thank Dr. T. Paskova (Linköping University) and Dr. R. Vaudo (ATMI) for samples, as well as Dr. S. Mitha and Dr. S. Novak (Chas. Evans and Associates) for SIMS profiles. The Lincoln Laboratory portion of this work was sponsored by the Office of Naval Research under Air Force Contact No. F19628-00-C0002. Opinions, interpretations, conclusions, and recommendations are those of the authors and are not necessarily endorsed by the United States Air Force. 
${ }^{1}$ S. Nakamura and G. Fasol, The Blue Laser Diode (Springer, Berlin, 1997).

${ }^{2}$ M. Razeghi and A. Rogalski, J. Appl. Phys. 79, 7433 (1997).

${ }^{3}$ J. Y. Duboz and M. A. Khan, in Group III Nitride Semiconductor Compounds, edited by B. Gil (Clarendon, Oxford, 1998), p. 343.

${ }^{4}$ H. P. Maruska and J. J. Tietjen, Appl. Phys. Lett. 15, 327 (1969).

${ }^{5}$ C. R. Miskys, M. K. Kelly, O. Ambacher, G. Martínez-Criado, and M. Stutzmann, Appl. Phys. Lett. 77, 1858 (2000).

${ }^{6}$ S. Fisher, C. Wetzel, E. E. Haller, and B. K. Meyer, Appl. Phys. Lett. 67, 1298 (1995).

${ }^{7}$ M. A. L. Johnson, Z. Yu, C. Boney, W. C. Hughes, J. W. Cook, J. F. Schetzina, H. Zhao, B. J. Skromme, and J. A. Edmond, Mater. Res. Soc. Symp. Proc. 449, 215 (1997).

${ }^{8}$ B. Monemar, J. Cryst. Growth 189/190, 1 (1998).

${ }^{9}$ W. Götz, J. Walker, L. T. Romano, N. M. Johnson, and R. J. Molnar, Mater. Res. Soc. Symp. Proc. 449, 525 (1997).

${ }^{10}$ D. C. Look and R. J. Molnar, Appl. Phys. Lett. 70, 3377 (1997).

${ }^{11}$ X. L. Xu, C. D. Beling, S. Fung, Y. W. Zhao, N. F. Sun, T. N. Sun, Q. L. Zhang, H. H. Zhan, B. Q. Sun, J. N. Wang, W. K. Ge, and P. C. Wong, Appl. Phys. Lett. 76, 152 (2000).

${ }^{12}$ G. Popovici, W. Kim, A. Botchkarev, H. Tang, H. Morkoc, and J. Solomon, Appl. Phys. Lett. 71, 3385 (1997).

${ }^{13}$ J. E. Van Nostrand, J. Solomon, A. Saxler, Q.-H. Xie, D. C. Reynolds, and D. C. Look, J. Appl. Phys. 87, 8766 (2000).

${ }^{14}$ L. T. Romano, B. S. Krusor, and R. J. Molnar, Appl. Phys. Lett. 71, 2283 (1997).

${ }^{15}$ S. H. Goss, A. P. Young, and L. J. Brillson, Mater. Res. Soc. Symp. Proc. 639, G3.59.1 (2001).

${ }^{16}$ M. Godlewski, E. M. Goldys, M. R. Phillips, R. Langer, and A. Barski, Appl. Phys. Lett. 73, 3686 (1998).

${ }^{17}$ R. A. Youngman and J. H. Harris, J. Am. Ceram. Soc. 73, 3238 (1990).

${ }^{18}$ J. I. Pankove and J. A. Hutchby, J. Appl. Phys. 47, 5387 (1976).

${ }^{19}$ S. Gu, R. Zhang, J. Sun, L. Zhang, and T. F. Kuech, Appl. Phys. Lett. 76, 3454 (2000).

${ }^{20}$ K. Fleischer, M. Toth, M. R. Phillips, J. Zou, G. Li, and S. J. Chua, Appl. Phys. Lett. 74, 1114 (1999).

${ }^{21}$ H. C. Yang, T. Y. Lin, and Y. F. Chen, Phys. Rev. B 62, 12593 (2000), and references therein.

${ }^{22}$ T. Paskova, E. M. Goldys, R. Yakimova, E. B. Svedberg, A. Henry, and B. Monemar, J. Cryst. Growth 208, 18 (2000).

${ }^{23}$ B. J. Skromme, J. Jayapalan, R. P. Vaudo, and V. M. Phanse, Appl. Phys. Lett. 74, 2358 (1999).

${ }^{24}$ B. Meyer, Mater. Res. Soc. Symp. Proc. 449, 497 (1997).

${ }^{25}$ M. Albrecht, S. Christiansen, G. Salviati, C. Zanotti-Fregonara, Y. T.
Rebane, Y. G. Shreter, M. Mayer, A. Pelzmann, M. Kamp, K. J. Ebeling, M. D. Bremser, R. F. Davis, and H. P. Strunk, Mater. Res. Soc. Symp. Proc. 468, 293 (1997).

${ }^{26}$ N. Grandjean, M. Leroux, M. Laügt, and J. Massies, Appl. Phys. Lett. 71, 240 (1997).

${ }^{27}$ S. Fischer, G. Steude, D. M. Hofmann, F. Kurth, F. Anders, M. Topf, B. K. Meyer, F. Bertram, M. Schmidt, J. Christen, L. Eckey, J. Holst, A. Hoffmann, B. Mensching, and B. Rauschenbach, J. Cryst. Growth 189/ 190, 556 (1998).

${ }^{28}$ S. Fischer, C. Wetzel, W. Walukiewicz, and E. E. Haller, Mater. Res. Soc. Symp. Proc. 395, 571 (1996).

${ }^{29}$ E. Calleja, M. A. Sanchez-Garcia, F. J. Sanchex, F. Calle, F. B. Naranjo, E. Munoz, Y. Jahn, and K. Ploog, Phys. Rev. B 62, 16826 (2000).

${ }^{30}$ M. Leroux, N. Grandjean, B. Beaumont, G. Nataf, F. Semond, J. Massies, and P. Gibart, J. Appl. Phys. 86, 3721 (1999).

${ }^{31}$ H. Siegle, A. Hoffmann, L. Eckey, and Thomsen, Appl. Phys. Lett. 71, 2490 (1997).

${ }^{32}$ B. K. Meyer, D. Volm, A. Graber, H. C. Alt, T. Detchprohm, A. Amano, and I. Akasaki, Solid State Commun. 95, 597 (1995).

${ }^{33}$ Chas. Evans and Associates, 810 Kaifer Road, Sunnyvale, CA 94086.

${ }^{34}$ D. C. Look, C. E. Stutz, R. J. Molnar, K. Saarinen, and Z. Liliental-Weber, Solid State Commun. 117, 571 (2001).

${ }^{35}$ D. Volm, K. Oettinger, T. Streibl, D. Kovalev, M. Ben-Choriin, J. Diener, B. K. Meyer, J. Majewski, L. Eckey, A. Hoffmann, H. Amano, I. Akasaki, K. Hiramatsu, and T. Detchprohm, Phys. Rev. B 53, 16543 (1996).

${ }^{36}$ K. Saarinen, T. Laine, S. Kuisma, J. Nissilä, P. Hautojärvi, L. Dobrzynski, J. M. Baranowski, K. Pakula, R. Stepniewski, M. Wojdak, A. Wysmolek, T. Suski, M. Leszczynski, I. Grzegory, and S. Porowski, Phys. Rev. Lett. 79, 3030 (1997).

${ }^{37}$ B. Monemar, J. Mater. Sci.: Mater. Electron. 10, 227 (1999); W. J. Moore, J. A. Freitas, Jr., and R. J. Molnar, Phys. Rev. B 56, 12073 (1997).

${ }^{38}$ B. Arnaudov, T. Paskova, E. M. Goldys, R. Yakimova, S. Evtimova, I. G. Ivanov, A. Henry, and B. Monemar, J. Appl. Phys. 85, 7888 (1999).

${ }^{39}$ A. P. Young, J. Schäfer, L. J. Brillson, Y. Yang, S. H. Xu, H. Cruguel, G. J. Lapeyre, M. A. L. Johnson, and J. F. Schetzina, J. Electron. Mater. 28, 308 (1999).

${ }^{40}$ K. Uchida, A. Watanabe, F. Yano, M. Kouguchi, T. Tanaka, and S. Minagawa, J. Appl. Phys. 79, 3487 (1996).

${ }^{41}$ M. Seelmann-Eggebert, H. Zimmermann, H. Obloh, R. Niebuhr, and B. Wachtendorf, Mater. Res. Soc. Symp. Proc. 468, 193 (1997).

${ }^{42}$ J. I. Pankove, Gallium Nitride I (Academic, San Diego, 1998).

${ }^{43}$ X. L. Sun, H. Yang, L. X. Zheng, D. P. Xu, J. B. Li, Y. T. Wang, G. H. Li, and Z. G. Wang, Appl. Phys. Lett. 74, 2827 (1999). 